\title{
PENERAPAN PROTOKOL RECRUITMENT PERAWAT BERBASIS KOMPETENSI DI RUMAH SAKIT SANTA ELISABETH MEDAN
}

\author{
Ernita Rante Rupang ${ }^{1}$, Nurmaini ${ }^{2}$, Roymond H. Simamora ${ }^{3}$ \\ ${ }^{1}$ Fakultas Keperawatan, Universitas Sumatera Utara Medan, Indonesia \\ ${ }^{2}$ Fakultas Kesehatan Masyarakat, Universitas Sumatera Utara Medan, Indonesia \\ ${ }^{3}$ Fakultas Keperawatan, Universitas Sumatera Utara Medan, Indonesia \\ Email: ellyrupangfse@gmail.com
}

\begin{abstract}
Abstrak
Protokol recruitment perawat berbasis kompetensi merupakan suatu pedoman dalam pelaksanaan recruitment perawat yang terdiri dari regulasi, pedoman, standar prosedur operasional (SPO). Penelitian ini bertujuan mengetahui pengaruh penerapan protokol recruitment perawat berbasis kompetensi di Rumah Sakit Santa Elisabeth Medan. Partisipan penelitian 16 orang. Metode penelitian: action research. Data kuantitatif yaitu tingkat pengetahuan partisipan diperoleh melalui penyebaran kuesioner dianalisis menggunakan statistik deskriptif diperoleh hasil adanya peningkatan pengetahuan sebelum dan sesudah pelaksanaan recruitment dengan menggunakan protokol recruitment berbasis kompetensi dari $80 \%$ menjadi 100\%. Data kualitatif diperoleh dari hasil FGD, analisa dengan content analysis. Dampak Penerapan Protokol recruitment perawat berbasis kompetensi di Rumah Sakit Santa Elisabeth Medan adalah perekrutan yang dilaksanakan lebih sistematis sesuai alur/prosedur yang telah ditetapkan; jumlah pelamar lebih banyak hasil dari perekrutan lebih bermutu.
\end{abstract}

Kata Kunci: Penerapan protokol, recruitment, perawat, kompetensi

\begin{abstract}
Implementation of Competency-Based Nurse Recruitment Protocol at Santa Elisabeth Hospital, Medan Competency-based recruitment protocols at the Santa Elisabeth hospital in Medan is a guideline in the implementation of nurse recruitment which consists of regulations, guidelines, standard operating procedur (SPO). This study aims to determine the effect of the application of competency-based recruitment protocol at the Santa Elisabeth hospital in Medan. Study participants were 16 people. Research methods: action research. Quantitative data that is the level of participant knowledge obtained through the distribution of questionnaires were analyzed using descriptive statistics obtained the results of an icrease in knowledge before and after implementation of recruitment using competency based recruitment protocols from $80 \%$ to $100 \%$. Qualitative data were obtained from FGD result, analysis with content analysis. The impact of the implementation of competency-based nurse recruitment protocols at the Santa Elisabeth hospital in Medan is the recruitment that is carried out more systematically according to the established procedures; the number of applicants more results from better quality recruitment.
\end{abstract}

Keywords: Aplication of protocols, recruitment, nurse, competency 


\section{Pendahuluan}

Rumah sakit merupakan institusi yang sangat kompleks dan berisiko tinggi (high risk) terlebih dalam kondisi lingkungan regional dan global yang perubahannya sangat dinamis (UU No. 44 tahun 2009, Pasal 46). Institusi yang kompleks memiliki arti bahwa rumah sakit memiliki tenaga kerja yang berasal dari disiplin ilmu pengetahuan yang berbeda-beda sehingga menuntut kerjasama satu sama lain. Seluruh tenaga kerja yang berasal dari disiplin ilmu yang berbeda tersebut diatur dalam Undang-Undang.

Tenaga kerja antar disiplin ilmu pengetahuan yang berbeda atau kerjasama antar profesi diatur dalam Undang-Undang Republik Indonesia Nomor 36 tahun tahun 2014. Tenaga keperawatan merupakan salah satu tenaga profesional yang kompleks di rumah sakit. Tenaga keperawatan memberikan layanan asuhan keperawatan, sehingga profesi perawat memiliki andil untuk mewujudkan kualitas pelayanan setiap saat.

Perawat adalah seseorang yang telah lulus pendidikan tinggi keperawatan, baik di dalam maupun di luar negeri yang diakui oleh pemerintah sesuai dengan ketentuan peraturan perundang-undangan (UU Keperawatan No. 38, 2014).

Salah satu upaya yang dilakukan untuk memperoleh tenaga profesional dan kompeten dalam memberikan layanan keperawatan yang berkualitas di rumah sakit adalah pelaksanaan recruitment. Menurut Dale (2008), recruitment adalah suatu proses mencari, memilih, menunjuk sumber daya manusia (SDM) yang tepat untuk sebuah pekerjaan baik permanen maupun sementara dalam suatu organisasi. Menurut Ofori dan Aryeetey dalam Edenborough (2012), recruitment adalah proses menghasilkan, mencari pelamar yang memenuhi syarat untuk lowongan pekerjaan organisasi.

Tujuan diadakannya recruitment adalah:1) untuk meningkatkan pool calon perawat memenuhi syarat seefisien mungkin; 2) untuk membantu meningkatkan keberhasilan proses seleksi dengan mengurangi calon perawat yang sudah jelas tidak memenuhi syarat atau yang terlalu tinggi kualifikasinya; 3) untuk membantu mengurangi kemungkinan keluarnya perawat yang belum lama bekerja; 4) untuk mengkoordinasikan upaya recruitment dengan program seleksi dan pelatihan; 5) untuk mengevaluasi efektif tidaknya berbagai teknik dan lokasi recruitment bagi perawat yang melamar kerja (Simamora, 2012).

Metode rekrutmen di Rumah Sakit Santa Elisabeth Medan adalah rekrutmen internal, dimana rumah sakit menunggu pelamar yang datang, yang merupakan lulusan dari sekolah milik yayasan rumah sakit ini. Rumah sakit lebih memprioritaskan lamaran yang berasal dari sekolah milik Yayasan Santa Elisabeth Medan walaupun calon pelamar yang di luar itu juga memiliki kesempatan untuk melamar ke Rumah Sakit Santa Elisabeth Medan (Nainggolan, 2011).

Penerimaan SDM dengan prioritas lulusan STIKes Santa Elisabeth menghasilkan perawat yang diterima lebih banyak yang baru tamat, belum berpengalaman, kurang kompeten dan juga kurang memiliki keunggulan kompetitif dibandingkan dengan pelayanan di rumah sakit yang lain. Meningkatnya turnover perawat khususnya yang masih menjalani tahap orientasi menjadi permasalahan di Rumah Sakit Santa Elisabeth Medan.

Tingginya jumlah SDM yang keluar pada bulan pertama menunjukkan adanya kesalahan pada pihak yang menerima. Kesalahan tersebut bisa terjadi karena SDM yang diterima tidak mencirikan atau menggambarkan kebutuhan ruangan. Kajian kebutuhan ruangan dengan SDM yang akan di supply ke ruangan yang membutuhkan merupakan kegiatan recruitment. Maka diharapkan agar pihak manajemen rumah sakit memberikan perhatian khusus pada pentingnya perencanaan dan proses pelaksanaan recruitment perawat. 
Penerapan protokol recruitment perawat berbasis kompetensi diharapkan membantu pihak manajemen Rumah Sakit Santa Elisabeth Medan untuk mendapatkan perawat yang profesional dan kompeten dalam memberikan layanan keperawatan.

\section{Metode Penelitian}

Metode pengumpulan data yang dilakukan adalah $F G D$ dan observasi. $F G D$ dilakukan bersama pihak manajemen rumah sakit yang sekaligus merupakan tim recruitment. Observasi dilakukan langsung dengan mengikuti proses recruitment perawat dengan penerapan protokol recruitment perawat berbasis kompetensi kemudian hasil observasi didokumentasikan. Proses recruitment dilaksanakan dari tanggal 29 April sampai dengan 22 Mei 2019.

\section{Hasil Penelitian}

Proses pelaksanaan recruitment perawat berbasis kompetensi di Rumah Sakit Santa Elisabeth Medan dilakukan selama 2 minggu dengan tahapan: 1) pengumuman penerimaan; 2) seleksi administrasi; 3) tes kesehatan; 4) ujian tulis; 5) uji skill; 6) wawancara; 7) penandatanganan kontrak kerja.

Tahapan pertama pengumuman penerimaan berlangsung dari tanggal 29 April hingga 12 Mei 2019 yang diawali dengan pemberitahuan melalui website Rumah Sakit Santa Elisabeth Medan; menyebarkan brosur melalui facebook, wattsapp; penyampaian surat ijin pemeritahuan ke 16 institiusi kesehatan di sekitar Medan. Jumlah pelamar sampai batas penerimaan adalah: 20 orang perawat dengan kualifikasi 3 orang ners dan 17 orang perawat vokasi.

Tahapan kedua seleksi administrasi dilakukan selama proses penerimaan berlangsung, jika ada perawat yang belum memenuhi kelengkapan administrasi maka diberi kesempatan selama 1 hari untuk melengkapi berkas yang kurang.
Tahapan ketiga tes kesehatan dilaksanakan pada tanggal 13 Mei 2019 bagi 20 perawat yang dinyatakan lulus seleksi administrasi. Hasil pemeriksaan kesehatan dari 20 orang adalah: yang direkomendasikan/lulus adalah 11 orang sedangkan 2 orang tidak lulus karena menderita TBC dan hepatitis; 7 orang tidak mengikuti tes kesehatan karena kendala biaya terlalu mahal.

Tahapan keempat ujian tulis dilaksanakan pada tanggal 15 Mei 2019 menggunakan naskah soal dari protokol untuk ners dengan tipe soal ners $\mathrm{C}$ dan untuk vokasi dengan kode soal D3(d). Pengumuman hasil uji tulis pada hari yang sama dengan bobot kelulusan sesuai standar pada protokol recruitment. Hasil uji tulis 11 orang perawat yang mengikuti ujian dinayatakan lulus dan selanjutnya berhak mengikuti uji skill.

Tahapan kelima uji skill dilaksanakan setelah pengumuman uji tulis dan diikuti oleh 11 orang perawat, uji skill dilakukan dengan menggunakan 12 core competency, untuk masing-masing assesi diuji 1 jenis tindakan keperawatan oleh assessor. Pengumuman disampaikan pada tanggal 16 Mei 2019. Hasil uji skill dari 11 orang perawat yang mengikuti ujian dinaytakan lulus dan berhak untuk mengikuti wawancara.

Tahapan keenam wawancara dilaksanakan pada tanggal 19 Mei 2019. Hasil wawancara 11 orang perawat yang mengikuti wawacara bagi yang dinyatakan lulus dan berhak untuk penandatanganan kontrak kerja untuk jangka waktu 1 tahun.

Tahapan ketujuh penandatanganan kontrak dilakukan oleh 11 orang yang telah lulus seleksi wawancara.

Untuk mengetahui pengaruh dari penerapan protokol recruitment perawat berbasis kompetensi di Rumah Sakit Santa Elisabeth Medan maka peneliti mengadakan $F G D$ dengan pihak manajemen rumah sakit yang terlibat langsung dalam pelaksanaan recruitment 
perawat di Rumah Sakit Santa Elisabeth Medan. Hasil FGD adalah:

a) Pendapat partisipan atau tim recruitment tentang alur recruitment dinyatakan partisipan dengan ungkapan berikut:

"Tapi dengan adanya pengumuman dari Web ini memang sangat bagus, jadi kita sekali menerima tidak seperti selama ini datang 1 atau 2 tidak tentu. Mulai dibukanya lowongan ini memang bagus sekali kalau dibatasi waktu, memang penerimaannya itu bulan april sama bulan oktober nanti paling tidak membuat kesempatan itu jangan lamalama, nanti melamar bulan januari menunggu lagi bulan 3 gimana orang sudah mencari tempat lari, jadi bukanya itu dekat-dekat dengan penerimaan. Jadi pas kemarin itu satu minggu atau 2 minggu untuk perekrutan.

"Kalau kita sudah pake informasi lowongan jelas iya kan, itu kan sudah bisa dibilang sampai tanggal berapa iya kan, jadi cocoknya memang seperti itu

"Iya karena memang harus sehat dulu baru bisa melayani

b) Manfaat dari penerapan protokol recruitment perawat berbasis kompetensi di Rumah Sakit Santa Elisabeth Medan dinyatakan partisipan dengan ungkapan berikut:

"Artinya ada perbedaan, kita kerja juga enak, gak nanya lagi habis itu kemana, kalau ini kan sudah jelas"

"Sesuatu yang sudah dialurkan tu kan jelas"

"Seperti selesai uji skill selama ini berapa hari baru diumumkan kan menambah waktu"
"Ini kan suatu kinerja juga itu”

\section{Pembahasan}

Proses Pelaksanaan recruitment perawat berbasis kompetensi dimulai dari pengumuman penerimaan, seleksi administrasi, tes kesehatan, uji tulis, uji skill, wawancara, penandatanganan kontrak kerja.

Penerimaan perawat di Rumah Sakit Santa Elisabeth Medan adalah: dengan menunggu pelamar dari instansi milik Yayasan Santa Elisabeth (Nainggolan, 2011).

Perubahan yang dilakukan dengan adanya protokol recruitment perawat berbasis kompetensi adalah pengumuman penerimaan disampaikan melalui website rumah sakit, penyebaran brosur melalui facebook dan WhatssApp serta penyampaian surat permitaan ijin pemberitahuan ke instansi di sekitar Medan maka pelamar yang didapatkan lebih banyak dan tidak hanya berasal dari instansi milik Yayasan Santa Elisabeth.

Seleksi administrasi dilakukan untuk melakukan verifikasi terhadap persyaratan administrasi yang disyaratkan. Seleksi administrasi langsung dilakukan ketika pelamar mengantarkan surat lamaran dan jika berkas tidak lengkap maka akan diberikan waktu satu hari untuk melengkapi berkas. hal ini sesuai dengan pendapat Simamora (2012), yang menyatakan bahwa seleksi administrasi berupa proses bagaimana perusahaan melakukan validasi dan verifikasi atas segala persyaratan administratif yang dipersyaratkan kepada calon tenaga kerja yang akan ditempatkan pada suatu jabatan tertentu.

Tes Kesehatan yang dilaksanakan adalah pemeriksaan kesehatan oleh tim medis yang telah ditentukan oleh manajemen Rumah Sakit Santa Elisabeth Medan. Dari hasil pemeriksaan kesehatan diperoleh hasil rekomendasi untuk menentukan pelamar yang diterima untuk mengikuti tahap selesi selanjutnya. Hal ini 
sesuai dengan pernyataan Hasibuan (2014), yang menyatakan: kesehatan sangat penting untuk menduduki suatu jabatan. Tidak mungkin seseorang dapat menyelesaikan tugas-tugasnya dengan baik jika sering sakit. Bahkan, perusahaan akan dibebani pengeluaran biaya perawatan yang cukup besar.

Kebihan dari cara ini adalah sebelum melalui tahap seleksi uji tulis pelamar sudah mengetahui status kesehatannya.

Kelemahan dari tahap ini adalah menjadi beban bagi pelamar karena kebijakan rumah sakit yang mengharuskan pelamar untuk menggunakan biaya sendiri untuk pemeriksaan kesehatan.

Uji Tulis dilaksanankan dengan naskah soal yang digunakan untuk ujian tulis adalah berdasarkan basis kompetensi, hal ini dimaksudakan agar pelamar yang diterima benar-benar memiliki kemampuan, pengetahuan sesuai dengan standar kompetensi. Menurut PPNI, 2005 Kompetensi adalah kemampuan seseorang yang dapat terobservasi mencakup pengetahuan, keterampilan dan sikap kerja dalam menyelesaikan suatu pekerjaan atau tugas sesuai dengan standar performa yang ditetapkan.

Wawancara dilakukan pada awal seleksi penerimaan sebelum diberlakukannya protokol Recruitment Perawat berbasis kompetensi namun setelah protokol diberlakukan maka wawancara dilakukan sebelum penandatanganan kontrak dengan maksud untuk memperoleh data yang lebih mendalam dari pelamar. Hal ini sesuai dengan pernyataan Sinambela (2018) bahwa wawancara adalah suatu pertemuan individu secara berhadapan untuk memperoleh informasi yang dikehendaki.

Kelebihan wawancara dilakukan pada tahap akhir adalah pewawancara dapat menggali informasi yang lebih mendalam sesuai dengan panduan yang tersedia, karena pelamar telah melewati tahap seleksi yang lebih berat. Simamora (2012), menyatakan bahwa kompetensi yang secara meyakinkan dapat diketahui melalui wawancara peristiwa perilaku yang singkat dan terarah.

Penandatanganan kontrak kerja dengan pemberlakuan protokol recruitment perawat berbasis kompetensi maka penadatanganan kontrak dilakukan setelah wawancara yang sebelumnya dilakukan setelah perawat yang telah lulus menyelesaikan masa orientasi.

Kelebihan cara ini adalah rumah sakit menerima karyawan untuk bekerja di Rumah Sakit Santa Elisabeth Medan sebagai karyawan kerja waktu tertentu Rumah Sakit Santa Elisabeth Medan, setelah dinyatakan lulus seleksi dan lansung menandatangani kontrak kerja.

\section{Simpulan}

Pengaruh penerapan protokol recruitment perawat berbasis kompetensi di Rumah Sakit Santa Elisabeth Medan adalah pengetahuan pihak manajemen rumah sakit semakin meningkat khususnya mengenai proses recruitment, hasil seleksi lebih bermutu, penggunaan waktu lebih efektif dan efisien.

Bagi rumah sakit penerapan protokol recruitment perawat berbasis kompetensi dalam proses recruitment sebagai tolok ukur kelulusan perawat yang melamar ke Rumah Sakit Santa Elisabeth Medan.

Bagi perawat diharapkan agar protokol recruitment perawat berbasis kompetensi, menjadi sumber pengetahuan dan peningkatan kompetensi dalam memberikan pelayanan yang profesional.

Bagi perkembangan riset keperawatan, hasil penerapan protokol recruitment perawat berbasis kompetensi menjadi salah satu data riset keperawatan (evidence based) yang dapat direkomendasikan untuk penelitian selanjutnya.

\section{Referensi}

Edenborough, R (2005). Assessment Methods In Recruitment, Selection \& Performance. 
Depkes RI (2014). Undang-Undang Republik Indonesia Nomor 38 Tahun 2014 Tentang Keperawatan.

Hasibuan, S.P. (2014). Manajemen Sumber Daya Manusia. Jakarta: Bumi Aksara

Kemmis, S., McTaggart, R., \& Nixon, R. (2014). The Action Research Planner: Doing Critical Participatory Action Research.

Nainggolan,S.C. (2011). Proses Rekrutmen Dan Seleksi Tenaga Keperawatan Dalam Peningkatan Mutu Pelayanan Keperawatan Rumah Sakit Santa Elisabeth Medan (Tesis). Jakarta: Universitas Indonesia Fakultas Kesehatan Masyarakat.

Ofori, D., Aryeetey, M., (2011). Praktek Rekrutmen dan seleksi di kecil dan menengah perusahaan. International. Journal of Business Administration, 2 (3): 45-60. Okoh, AO

Simamora R. H (2012). Buku Ajar Manajemen Keperawatan. Jakarta: EGC

Sinambela, L. (2016). Manajemen Sumbar Daya Manusia. Jakarta: PT Bumi Aksara

Kemenkes RI. (2009). Undang-Undang Republik Indonesia Nomor 44 Tahun 2009 tentang Rumah Sakit. Jakarta

Kemenkes RI. (2014). Undang-Undang Republik Indonesia Nomor 36 tahun 2014 tentang tenaga kesehatan. Jakarta

Kemenkes RI. (2014). Undang-Undang Republik Indonesia Nomor 38 Tahun 2014 tentang keperawatan. Jakarta
Wijayanti, R. (2013). Gambaran Rekrutmen Dan Seleksi Pegawai Di Rumah Sakit Umum Pusat Nasional Dr. Cipto Mangunkusumo. Depok: FKM UI 